Ärztliche Erfahrung beschränkt sich nicht auf medizinisches Fachwissen.

Sie entsteht auch aus den mehr oder minder alltäglichen, heiter, ärgerlich oder nachdenklich stimmenden Erlebnissen mit Patienten, Kollegen und Mitarbeitern. Senden Sie uns Ihre Geschichte an: cornelius.heyer@springer.com.

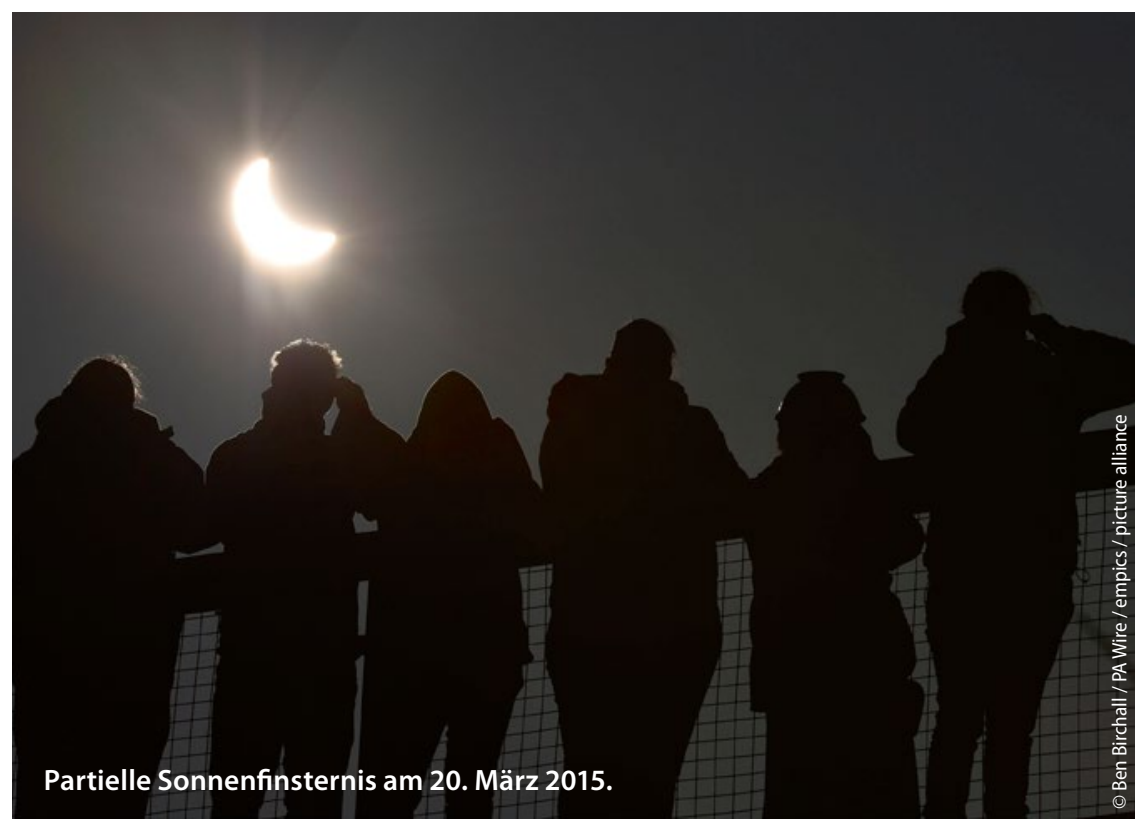

\section{Die SoFi-Brille aus dem Praxisfundus}

_ Was kann man bloß tun, wenn zur absoluten Sprechstundenstoßzeit eine Sonnenfinsternis zu bewundern ist? Diese Frage hatten wir uns aus naheliegenden Gründen nie gestellt - bis es dann am 20. März dieses Jahres unvermittelt soweit war. Bereits eine Stunde vor Eintritt der Erde in den Schatten des Mondes war ein aufgeregtes Gezwitscher und Gekrächze der Vögel zu hören. Nun wurde das Licht kälter und trüber. Es wurde stiller draußen. Unheimlich.

Dieses kosmische Superereignis wollte ich mir keinesfalls entgehen lassen. Doch wie sollte das gehen? Mit einem Notfallhausbesuch konnte ich mich nicht rausreden, denn man hätte mich ja beim Betrachten der Sonne sicherlich erwischt. $\mathrm{Zu}$ allem Überfluss waren die Spezialbrillen in Darmstadt längst aus-

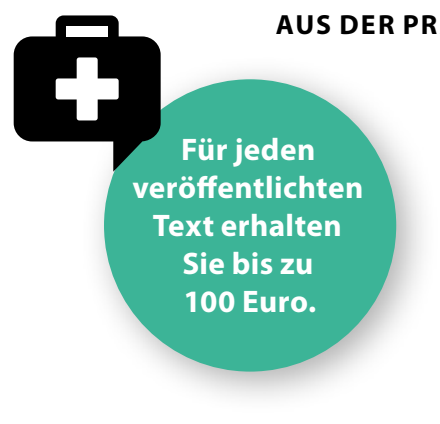

Verstehen Sie sich mit Menschen aller Nationen? Jo!

_ Vater und Sohn aus Albanien kamen in die Praxis. Der Vater sprach kein Wort Deutsch, der Sohn dafür perfekt, denn er arbeitet schon lange bei einer großen Raumfahrtbehörde in Darmstadt. Dem Vater gehe es schlecht, er beklage sich über Bauchschmerzen, berichtete der Sohn. „Fragen Sie mich!“, befahl er dann. „Ich übersetze!“

So machten wir es. Der Vater saß wie eine Statue daneben. Da wollte ich ihn doch ein bisschen in das Gespräch einbeziehen, es ging ja schließlich auch um ihn. „Lassen Sie mich mal“, sagte ich siegessicher meinem Dolmetscher, denn ich glaube, dass ich mich mit Menschen aller Nationen verstehe. Ich bediente mich einfachster Körpersprache, um den Vater zu fragen, ob er rauche. "Jo“, sagte der sofort - zugleich sagte der Sohn aber: „Nein!“”

Naja, der Junge muss ja nicht alles wissen, dachte ich mir. Seinem Doktor muss man eben die Wahrheit sagen, auch wenn sie unbequem ist, und jetzt kommt es hier heraus: Der Vater raucht! Doch der Sohn insistierte, dass dies nicht der Fall sei. „Hat er doch gesagt“, meinte ich. „Nein“, sagte der Sohn, und forderte wieder: „Lassen Sie bitte mich übersetzen!“

Und dann dämmerte es mir allmählich: „Sagen Sie mal, was heißt ,Nein' auf Albanisch?", fragte ich den Sohn. „Jo“" bekam ich zur Antwort. Und dann nickten die beiden auch noch dabei!

Dr. Luise Hess, Darmstadt 